DOI: $10.14451 / 1.202 .71$

\title{
МЕХАНИЗМ ПОСТРОЕНИЯ БИЗНЕС-МОДЕЛИ СЕРВИСНОЙ КОМПАНИИ ПО ОБСЛУЖИВАНИЮ РАДИОНАВИГАЦИОННОГО ОБОРУДОВАНИЯ
}

\author{
(c) 2021 Воронова Ольга Владимировна \\ кандидат экономических наук, доцент \\ Санкт-Петербургский политехнический университет Петра Великого, Россия, Санкт-Петербург
}

(c) 2021 Хныкина Татьяна Семеновна

кандидат экономических наук, доцент

Санкт-Петербургский политехнический университет Петра Великого, Россия, Санкт-Петербург

(c) 2021 Ильина Ирина Витальевна

ассистент

Санкт-Петербургский политехнический университет Петра Великого, Россия, Санкт-Петербург

\section{(c) 2021 Орлова Валерия Игоревна}

магистрант

Санкт-Петербургский политехнический университет Петра Великого, Россия, Санкт-Петербург

В данной статье рассмотрен механизм построения бизнес-модели сервисной компании по обслуживанию радионавигационного оборудования по методике А. Остервальдера и И.Пинье. В процессе исследования был проведен анализ рынка действующих сервисных фирм, обслуживающих радионавигационное оборудование на судах водного транспорта, рассмотрены особенности территориального расположения бизнеса, виды услуг, оказываемых на рынке сервисного обслуживания радионавигационного оборудования, характер правового регулирования, а также факторы, отрицательно влияющие на результативность деятельности компаний, и основные направления долгосрочного развития сервисных компаний, открывающие возможности для их роста и развития. В процессе исследования рассмотрены основные этапы построения бизнес-модели отдельно по каждому из девяти ключевых показателей. Используя методический подход, предложенный А. Остервальдером и И.Пинье, и обзор рынка аналогичных сервисных услуг, в результате исследования представлена бизнес-модель сервисных компаний по обслуживанию судового радионавигационного оборудования с учетом специфики рынка, на котором они функционируют.

Ключевые слова: бизнес-модель, моделирование, ключевые элементы бизнес-модели, ключевые ресурсы, ценностное предложение, каналы распространения, сегменты клиентов, сервисные услуги, радионавигационное оборудование.

\section{1. Введение}

Есть множество определений понятия «бизнес-модель». Если проанализировать существующие в литературе трактовки данного термина, то общая идея сводится к тому, что бизнес-модель - это логическое и наглядное описание того, каким образом компания выстраивает свои процессы, чтобы создавать ценность для клиентов и получать от этого прибыль. Для работающих фирм она является важнейшим инструментом стратегического управления, который используется для поиска новых точек роста, анализа внешней среды, разработки ценностных предложений и определения лучших практик развития бизнеса.

Все компании вне зависимости от своего вида и формы бизнеса имеют одну общую черту: они создают и приносят пользу своим клиентам. Поскольку организации не могут существовать без потребителей своих товаров или услуг, в основе каждой бизнес-модели лежит определение рынка, для которого фирма создает ценность. Именно поэтому построению модели бизнеса всегда должен предшествовать анализ отрасли, отраслевой бизнес-системы, а также тенденций и основных направлений их развития.

Рынок компаний, поставляющих и обслуживающих различное радионавигационное оборудование и средства связи, играет большое значения в обеспечении безопасности судоходства и мореплавания. Это связано с тем, что для гарантирования максимальной надежности в море и 
на внутренних водных путях и предупреждения аварийных ситуаций необходима безотказная и точная работа всего оборудования на судне. Особенно это касается судовой радиосвязи и навигации. По статистике, в 2020 году около 25\% транспортных происшествий на море составляли навигационные аварийные случаи, связанные со столкновениями, навалами, посадками судов на мель. На внутренних водных путях на долю подобного вида происшествий приходилось 78\% случаев [1]. Именно поэтому одной из главных мер, предпринимаемых по предупреждению аварийных ситуаций, является оснащение морского транспорта качественным радионавигационным оборудованием. Ответственность за работу подобных устройств берут на себя сервисные компании.

\section{2. Результаты}

На сегодняшний день в данном сегменте рынка работает множество организаций по всей России, но большинство фирм естественным образом сосредоточены рядом с важнейшими портами страны. Превалирующее число сервисных компаний базируются в Санкт-Петербурге, именно там сосредоточен крупнейших транспортный узел на северо-западе России - Mopской порт Санкт-Петербург. Именно в этом городе осуществляют свою деятельность самые известные и крупные компании страны, а именно: ГК «Морская техника», ГК «Связь и Радионавигация», ООО «Маринэк» и другие. На втором месте по количеству действующих сервисных компаний находится город Владивосток [2].

Есть множество направлений, в рамках которых данные организации осуществляют свою деятельность: начиная с поставок различного судового оборудования, его установки и ремонта и заканчивая разработкой собственной линейки устройств. На рисунке 1 представлены одни из основных видов услуг, оказываемых сервисными компаниями на рынке.

Сервисное обслуживание - это фундамент деятельности любой компании, функционирующей на данном рынке. Им занимаются специалисты отдела сервиса, инженеры, которым присваиваются различные категории в зависимости от стажа работы и наличия определенных навыков и знаний.

На рисунке 2 наглядно представлена динамика выручки от реализации услуг по ремонту и техническому обслуживанию судов и лодок (код ОКВЭД - 33.15, не включает ремонт судов и корабельных двигателей). Это один из кодов классификатора, под который подпадает деятельность сервисных компаний. По данным Росстата, объем выручки организаций в 2018 году резко увеличился на 22,6\%, после чего наблюдался незначительный спад продаж сервисных услуг в 2019 году на 4,1\%, или на 3176,9 млн. руб. [4]. Причин, повлекших за собой падение показателя выручки, достаточно много. Это могло произойти вследствие снижения спроса на услуги или на фоне общего экономического спада в стране. Еще одним фактором, который мог привести к торможению деятельности компаний, является рост фискальной нагрузки, выраженный увеличением ставки НДС с 18 до 20\%.

Чтобы успешно осуществлять деятельность на рынке сервисного обслуживания радионавигационного оборудования, компаниям необходимо получить сертификаты одобрения на весь спектр выполняемых работ. Их выдачей

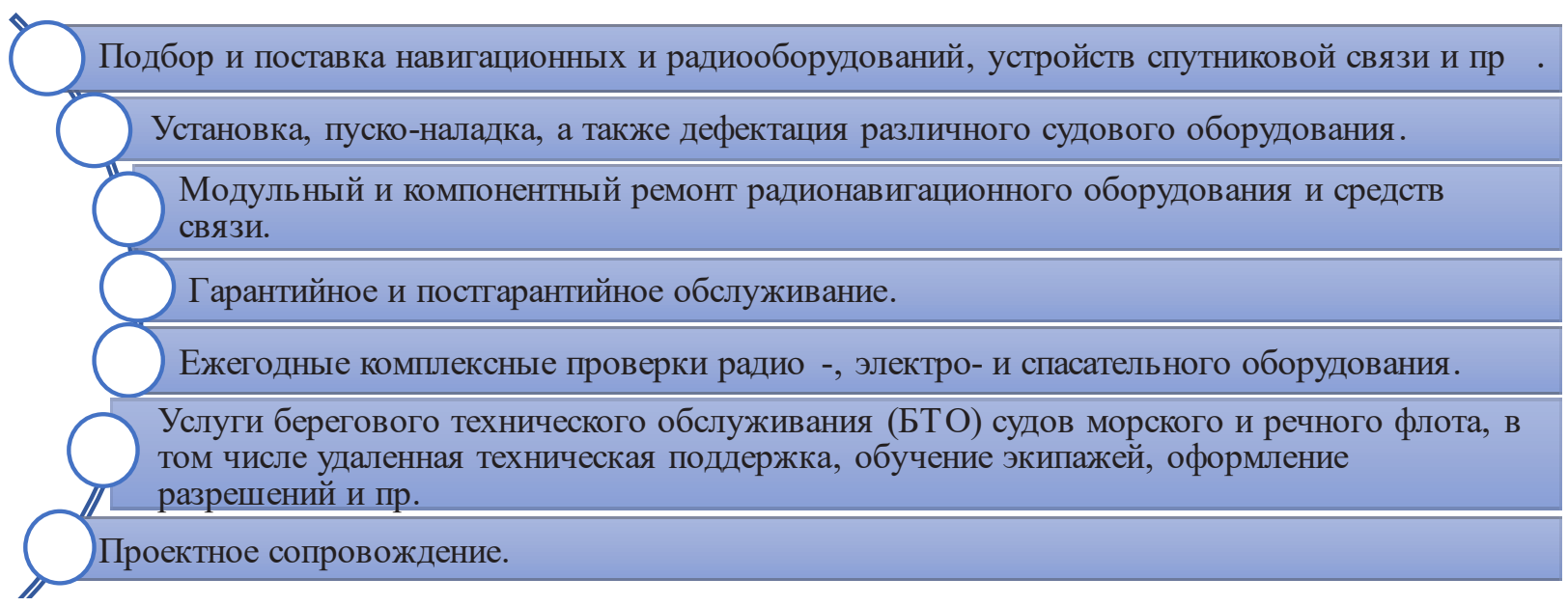

Рисунок 1. Виды услуг, оказываемых на рынке сервисного обслуживания радионавигационного оборудования [3] 


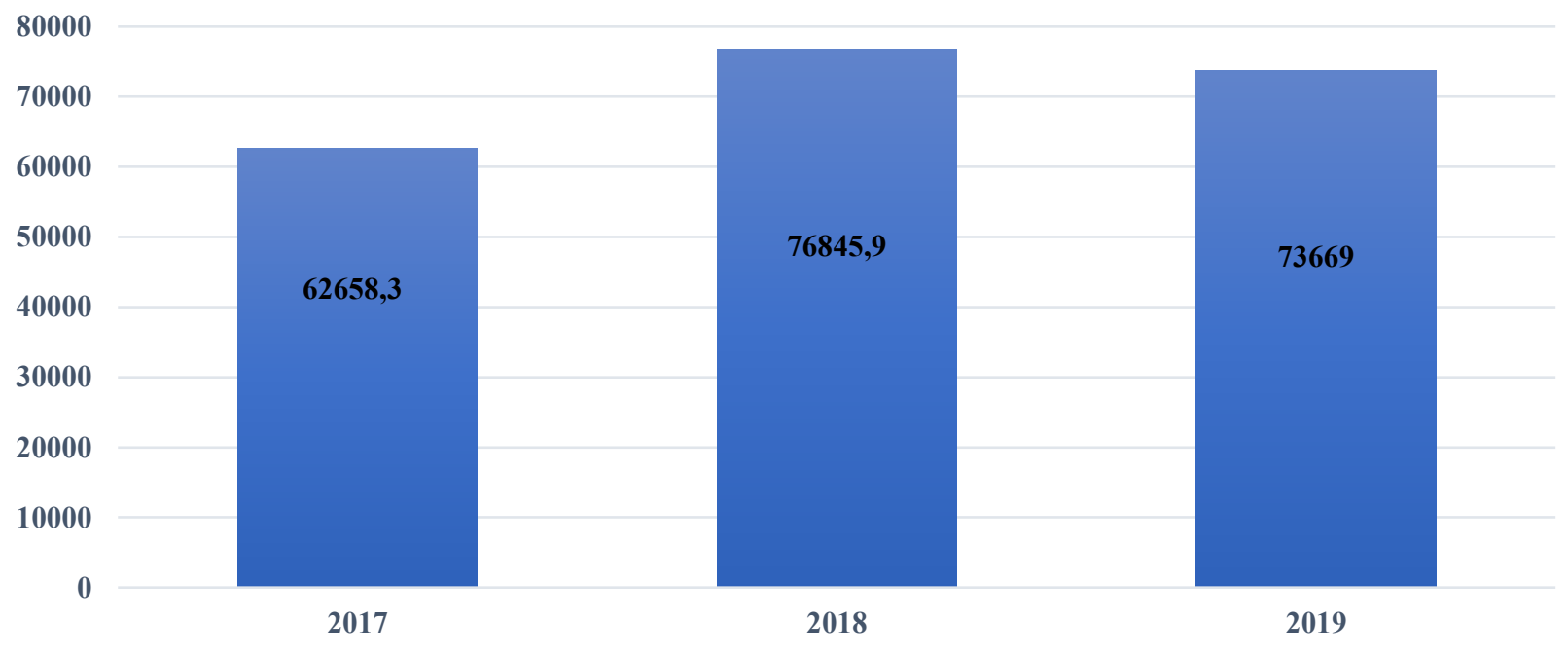

Рисунок 2. Динамика объема выручки от оказания услуг по ремонту и техническому обслуживанию судов и лодок в 2017-2019 годах в стоимостном выражении [5]

занимаются подведомственные Министерству транспорта Российской Федерации международное классификационное общество «Российский морской регистр судоходства» и федеральное автономное учреждение «Российский речной регистр» [6,7].

Пройдя обязательную сертификацию, сервисная компания получает следующие свидетельства:

- о признании (документ, подтверждающий признание того, что предприятие оказывает услуги в соответствии с требованиями Морского/ Речного регистра);

- о соответствии предприятия (документ, подтверждающий, что оказываемые предприятием услуги соответствуют требованиям Регистра Судоходства/ Речного регистра).

Также, чтобы гарантировать международное признание своей деятельности, компании могут получить сертификаты крупнейших иностранных классификационных обществ, таких как DNV-GL, Lloyd's Register, ABS, BV, ClassNK, RINA и т.д. Полученные документы подтверждают для организации статус признанного поставщика услуг для судов и предоставляют возможность для работы с новыми технологиями и инновациями в морском секторе, которые помогают загазчикам достигать высоких показателей работы в судоходстве и кораблестроении [8].

Помимо оказания услуг, связанных с обслуживанием радионавигационного оборудования, немаловажным направлением работы сервисных организаций является продажа различных устройств радиосвязи и навигации. В основном компании заключают дилерские и дистрибью- торские соглашения с отечественными и зарубежными производителями, получая тем самым статус официального представителя и сервисного партнера. Самыми известными российскими изготовителями являются ООО «Группа Транзас» и Пермская научно-производственная приборостроительная компания («ПНППК»). Среди иностранных компаний выделяются: Furuno, JRC, Sperry Marine, Sailor и другие [9].

Что касается объема импорта радионавигационной аппаратуры (код ТН ВЭД - 852691), то из рисунка 3 видно, что с 2016 по 2019 год размер импортных поставок сохранял положительную динамику, рекордный темп роста за анализируемый период наблюдался в 2017 году (143,7\%) [10]. Однако, в отчетном году объем импорта резко снизился на 27,2\% и составил 1,4 млн. единиц радионавигационной аппаратуры, а в стоимостном выражении - 189,4 млн. дол. США [11]. Такой спад произошел на фоне распространения коронавирусной инфекции (COVID-19) и резкого сокращения трансграничной торговли. Из-за необходимости ввода ограничительных мер в ключевых странах-партнерах в области импорта радионавигационной аппаратуры до рекордно низкого уровня упала производственная активность в первом квартале отчетного года, что негативно сказалось на показателях внешней торговли. Это касается Сингапура, обеспечившего 20,5\% поставок в 2020 году, Китая (13,1\%), а также Вьетнама $(11,4 \%)$ и других стран [12].

Так как фирмы функционируют в рамках обширной макросреды, необходимо также проанализировать влияние факторов, которые открывают для сервисных компаний новые воз- 


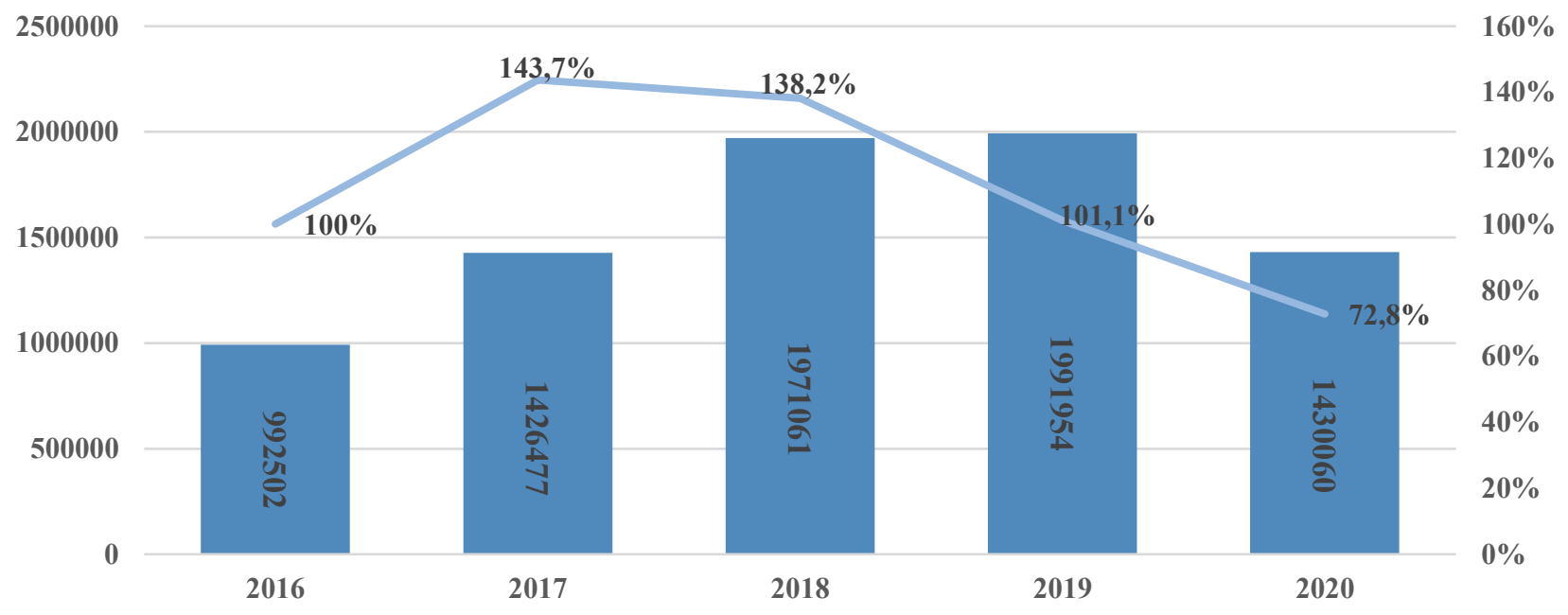

Рисунок 3. Динамика импорта радионавигационной аппаратуры в 2016-2020 гг. в натуральном выражении [13]

можности либо грозят им новыми опасностями. Ключевым сдерживающим фактором текущего развития анализируемых фирм является негативное влияние пандемии. Большинство организаций, действующих на данном рынке, оказывают услуги не только в пределах России, но и за рубежом. Вследствие закрытия границ для перемещения людей, компании потеряли немаловажный источник дохода, который приходился на заграничные командировки сотрудников с целью выполнения заявок для иностранных судовладельцев и судоходных организаций.

Кроме того, география работы судовладельцев привязана к фрахтам, контрактам, рейсовым заданиям, различным политическим факторам,- в любой момент времени судно заказчика может работать в порту России, через неделю перебраться заграницу и т.д. Поэтому сервисная компания должна развивать свое региональное присутствие в базовых регионах страны с развитым судоходством [14]. Это позволит фирме организовать оперативный и качественный сервис и обеспечить себе конкурентоспособность на рынке.

\section{3. Обсуждение}

Помимо расширения географии присутствия существуют и другие направления долгосрочного развития сервисных компаний. Среди них можно выделить:

1. Адаптация ассортимента предлагаемых услуг и товаров в соответствии с технологическим развитием рынка судового оборудования. Например, сейчас в морскую отрасль активно внедряются технологии безэкипажного судовождения [15]. Увеличение степени автономности судна требует оснащение его усовершенствованными системами обеспечения безопасности и накладывает дополнительную ответственность на сервисные компании за качественную и надежную установку и обслуживание оборудования.

2. Формирование отдельных торговых предложений для «стареющего» флота (то есть для морских и речных судов, оборудованных старыми советскими устройствами, которые давно выработали свой конструктивный и технический ресурс, и нуждаются в обновлении).

3. Организация производства собственной линейки оборудования исходя из потребностей рынка и особенностей самой компании. Плюсы проектирования собственных устройств заключаются не только в гибком подходе к процессу разработок, но и в удобном и ускоренном сервисе разработанного оборудования на этапе эксплуатации.

Используя методический подход, предложенный А. Остервальдером и И.Пинье, и результаты обзора рынка, представим бизнес-модель сервисной компании на примере одной из ведущих фирм в области обслуживания радионавигационного оборудования - ГК «Связь и радионавигация» (см. рис. 4). На сегодняшний день данная компания является лидером по числу инженеров среди своих конкурентов в сфере обслуживания связи и навигации. Фирма выполняет более 2500 заявок в год по всему миру и готова предложить 95\% номенклатуры всего навигационного и радиооборудования, которое сегодня представлено на российском гражданском флоте. 


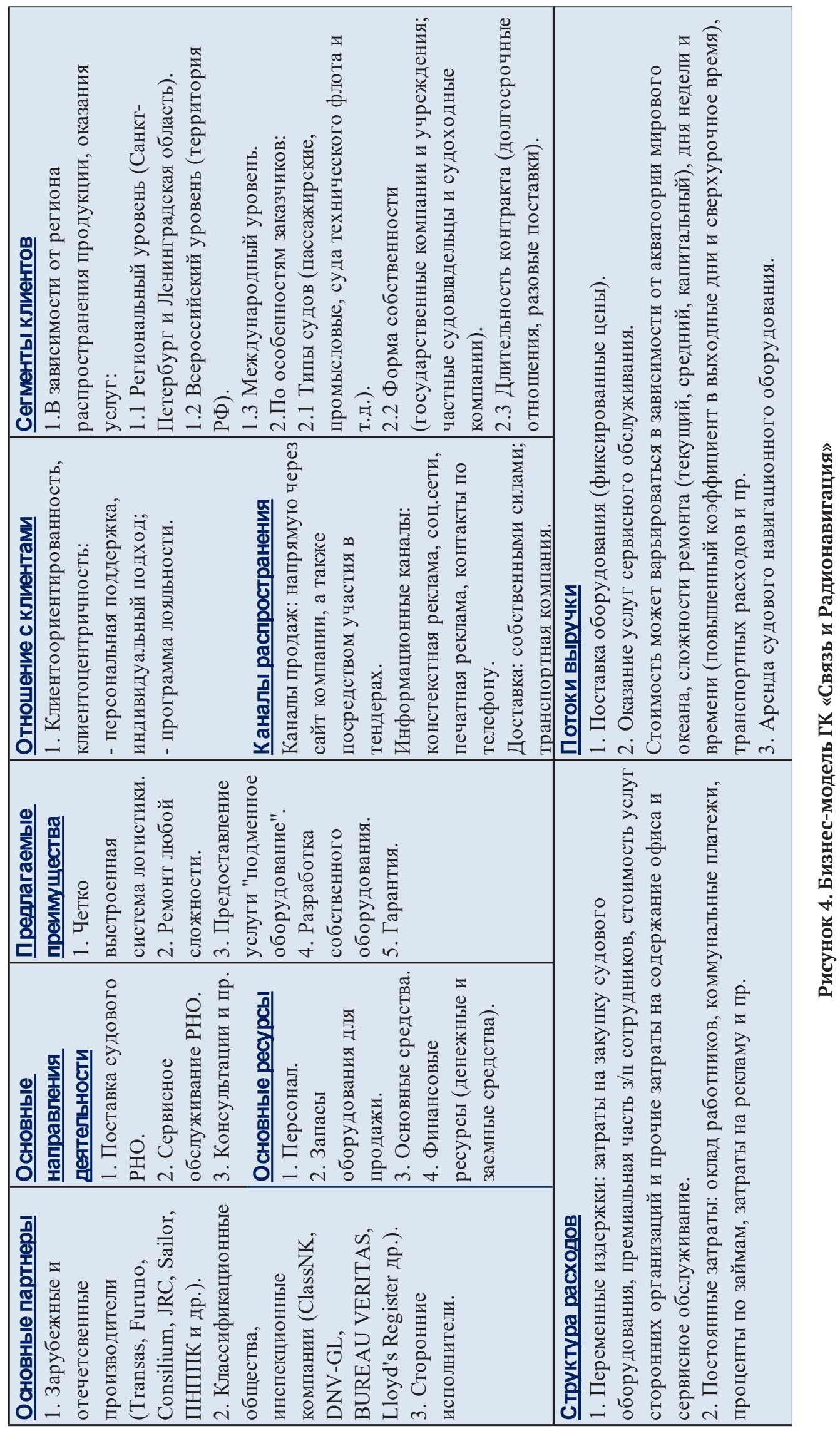




\section{4. Заключение}

Согласно выбранной методике, модель ГК «Связь и Радионавигация» включает в себя девять блоков, которые описывают логику действий организации, направленных на удовлетворение потребностей заказчиков, получение прибыли и обеспечение конкурентоспособности на рынке с помощью предлагаемых конкурентных преимуществ.

Из представленной схемы видно, что компания отличается на рынке высокой скоростью поставки оборудования (благодаря наличию складской сети в России и транзитного склада в Европе) и оперативным обслуживанием (за счет развитого регионального присутствия).

Помимо выполнения ремонта любой сложности, который экономит клиенту до 70\% стоимости оборудования, ГК «Связь и Радионавигация» предлагает уникальную на рынке услугу - «Ремонт с подменой», которая заключается в сдаче в аренду принадлежащих компании судовых устройств на время ремонта оборудования заказчика.

Также фирма с недавнего времени начала заниматься разработкой собственной линейки вспомогательных устройств, которые позволяют совмещать между собой оборудования разных производителей, а также старых приборов с более совершенными. Близость разработчиков компании к бизнес-процессам, опыт сотрудников и знание всех нюансов в области обслуживания различного рода оборудования позволяет организации мгновенно подстраиваться под изменяющиеся запросы и требования заказчиков и тем самым обеспечивать себе конкурентное преимущество на рынке.

Главный ресурс в компании - это персонал, который представлен специалистами коммерческой и сервисной служб. Первые ответственны за логистические процессы, закупку и продажу оборудования заказчикам, вторые - за качественное и оперативное сервисное обслуживание.

Что касается отношений с клиентами, компания избрала для себя модель персональной поддержки, основанную на личных контактах с каждым заказчиком товаров или услуг. Так как линейка оборудования, представленная на борту судна, бывает совершенно разнородной, отсюда вытекают разные потребности и задачи клиен- тов, которые необходимо решать с помощью персонального взаимодействия и на основе комплексного подхода как с точки зрения поставки оборудования, так и в части оказания сервиса. А чтобы развивать более глубокие и длительные отношения с заказчиками, компания предоставляет программу лояльности (1\% от покупки начисляется в виде баллов, ими можно оплачивать до 100\% стоимости сервисных услуг) и гарантию на все выполненные работы.

Чтобы поддерживать свою конкурентоспособность, фирма должна постоянно подстраиваться под изменения, происходящие во внешней среде. Адаптивность компании достигается прежде всего путем выстраивания грамотной системы стратегического и оперативного управления. В частности, это касается разработки эффективной ассортиментной политики и гибкого процесса обучения персонала для регулярного обновления знаний и навыков в области продажи и обслуживания радионавигационного оборудования.

Компания должна по возможности внедрить механизмы адаптации, которые представляют собой совокупность инструментов, способствующих оперативной перестройке всех или части элементов бизнес-модели с целью поддержания удовлетворенности и лояльности заказчиков и обеспечения финансовой устойчивости в условиях постоянно меняющейся бизнес-среды.

В заключении еще раз нужно подчеркнуть, что рынок сервисного обслуживания судового оборудования не стоит на месте. Парк водного транспорта ежегодного пополняется новыми и более технологичными морскими и речными судами, с каждым днем появляются все более совершенные устройства, а вместе с ними и новые потребности, под которые нужно подстраивать деятельность фирм, адаптировать и дополнять предлагаемые для рынка услуги. Наряду с этим требует своего пересмотра и бизнес-модель компании, главная цель которой состоит в обеспечении ей эффективного функционирования и стабильного положения на рынке сервисных услуг. А это, в свою очередь, будет в значительной степени зависеть от выстраиваемой системы управления и способностей бизнес-модели приспосабливаться к изменяющейся внешней среде. 


\section{Библиографический список}

1. Сведения об аварийности с судами на море и внутренних водных путях в 2020 году. [Электронный ресурс] / Госморречнадзор.- URL: http://surl.li/sqfy (дата обращения: 15.05.2021).

2. Презентация ГК Сu P. [Электронный ресурс] / Группа компаний Связь и Радионавигация. - URL: https:// drive.google.com/file/d/1RNCJ3WBGmJ-1Xi3mSzqmCys2YNDYnD6Y/view (дата обращения: 16.05.2021).

4. Воронова, О.В. Методологические основы формирования системы требований к архитектуре сервисов сетевых торговых компаний // Известия Санкт-Петербургского государственного экономического университета.-2020.- № 5(125).-С. 117-124.

3. Единая межведомственная информационно-статистическая система (ЕМИСС). [Электронный ресурс] / Федеральная служба государственной статистики (Росстат). - URL: https:/www.fedstat.ru/indicator/58235\# (дата обращения: 13.05.2021).

4. Таможенная статистика внешней торговли РФ. [Электронный ресурс] / CustomsOnline.- URL: https:// customsonline.ru/search_ts.html (дата обращения: 17.06.2021).

5. Воловик К. Радиосвязь и навигация - это залог безопасности мореплавания // Информационный морской журнал Korabel.ru._ 2020._- № 3. URL: https://www.korabel.ru/news/comments/radiosvyaz_i_navigaciya_-_eto_ zalog_bezopasnosti_moreplavaniya.html (дата обращения: 17.05.2021).

5. Воронова, О.В. Референтная модель бизнес-процессов верхнего уровня для построения архитектурных решений сетевых компаний FMCG-ритейла // Экономика и управление. - 2019. - № 5(163). - C. 81-88.

6. Фролов В.Н., Севбо В.Ю. Технологии безэкипажного судовождения//Транспорт российской федерации.2018. - № 4.- c. 17-21. URL: https://cyberleninka.ru/article/n/tehnologii-bezekipazhnogo-sudovozhdeniya/ viewer (дата обращения: 16.06.2021).

7. Репин, В.В. Бизнес-процессы. Моделирование, внедрение, управление / - М.: Манн, Иванов и Фербер, 2019.- 512 c.

8. Ширяев, В.И. Управление бизнес-процессами / учеб-метод. пособие - М.: ИНФРА-М, 2019. - 464 с.

9. Бирюков, В.В. Бизнес-модель в стратегическом управлении промышленным предприятием // Вестник Омского университета. Серия: Экономика.- 2020.- T. 18.- № 1.- C. 69-76.- DOI 10.24147/18123988.2020.18(1).69-76.

10. Остервальд А., Пинье И. Построение бизнес-моделей [Электронный ресурс] / ООО «Альпина Паблишер».Электрон. изд., 2012.- URL: https:/clck.ru/Ufb8C (дата обращения: 21.06.2021)

11. Вахрушина, M.А. Бизнес-модель как современный объект управленческого учета // Бухгалтерский учет и налогообложение в бюджетных организациях. - 2021.- № 2.- С. 5-11.

12. Левина, А.И. Функционально-ориентированное проектирование информационных систем инфраструктурно-емких предприятий // Перспективы науки. - 2018. - № 11(110). - С. 35-39.

13. Безверха, О. Бизнес-модель как инструмент создания устойчивых конкурентных преимуществ // Вестник КазЭУ.-2013. - № 3(93).- С. 91-99.

14. Меркушова, Н. И. Использование конструкта «бизнес-модель» в современном предпринимательстве // Вопросы экономики и управления. - 2015.- № 2(2).-С. 100-105.

15. Ксенофонтова, Х.З. Бизнес-модель - источник формирования конкурентоспособности промышленных компаний в условиях перехода к цифровой экономике // Fortus: экономические и политические исследования. - 2018. - № 2(2). - С. 1-7.

16. Khareva, V. Development of a Reference Model for the «purchase» Business Process as an Element of Modeling Basic Business Processes at FMCG Chain Retailing Companies // IOP Conference Series: Materials Science and Engineering, St.Petersburg, 21-22 ноября 2019 года.- St.Petersburg, 2020.- P. 012057.- DOI 10.1088/1757899X/940/1/012057. 